\title{
SINERGIA
}

REVISTA DO INSTITUTO DE CIÊNCIAS ECONÔMICAS, ADMINISTRATIVAS E CONTÁBEIS (ICEAC)

\section{LIVROS DE AUTO-AJUDA EM FINANÇAS PESSOAIS DE AUTORES BRASILEIROS E NORTE- AMERICANOS: ANÁLISE DE CONTEÚDO DOS BEST-SELLERS DA ÁREA (2010 - 2019)}

SAMIR SAYED

FLÁVIA MAIRA SILVA*

\section{RESUMO}

O trabalho procurou comparar os livros mais vendidos de autores brasileiros e norte-americanos de autoajuda em finanças pessoais com intuito de identificar algum tipo de padrão nas respectivas literaturas e possíveis explicações para os fenômenos identificados, utilizando a técnica de Análise de Conteúdo de Bardin (1977). A codificação utilizada foi baseada na estrutura conceitual do Planejamento Financeiro Pessoal do Financial Planning Standards Board. O estudo tem suas hipóteses baseadas em dados oficiais de acesso ao mercado financeiro, na dificuldade financeira das populações e nos níveis de educação financeira. Os resultados rejeitaram parcialmente a hipótese, já que em ambas as literaturas o foco se deu em gestão de ativos e investimentos, porém a amplitude para a codificação planejamento financeiro nos autores brasileiros é significativamente menor que nos norte-americanos. Estes evidenciam o fato dos consumidores desse tipo de literatura ter interesse direto sobre os temas ligados a essa codificação e estão inseridos (ou pretendendo se inserir) no mercado de investimentos, buscando conhecimento específico. Além disso, mostra certo mimetismo por parte da literatura oriunda de autores brasileiros, que poderia entender o mercado norteamericano como um modelo (de sucesso) ou influência direta dos autores e livros deste país cuja literatura é mais antiga e robusta.

Palavras-chave: Educação financeira, Finanças Pessoais, Planejamento Financeiro Pessoal.

\section{ABSTRACT}

The work sought to compare the best selling self-help books by Brazilian and North American personal finance authors in order to identify some type of pattern in the respective literature and possible explanations for the identified phenomena, using Bardin's Content Analysis technique (1977). The coding used was based on the conceptual framework of the Financial Planning Standards Board's Personal Financial Planning. The study has its hypotheses based on official data on access to the financial market, on the financial difficulties of the populations and on the levels of financial education. The results partially rejected the hypothesis, since in both literature the focus was on asset and investment management, however the scope for coding financial planning in Brazilian authors is significantly less than in North Americans. These evidence the fact that consumers of this type of literature have a direct interest in the themes related to this codification and are inserted (or intending to insert themselves) in the investment market, seeking specific knowledge. In addition, it shows a certain mimicry on the part of the literature coming from Brazilian authors, who could understand the North American market as a (successful) model or direct influence of the authors and books of this country whose literature is older and more robust.

Keywords: Financial education, Personal Finance, Personal Financial Planning.

Recebido em: 27-05-2020 Aceito em: 12-06-2020

\section{INTRODUÇÃO}

A importância da educação financeira é apontada e trabalhada por vários órgãos nacionais e internacionais, como por exemplo, a iniciativa da Organização para Cooperação e Desenvolvimento Econômico (OCDE) que trata a educação financeira como prioridade política dos países (OCDE, 2017).

O estágio de desenvolvimento que se encontra a educação financeira no Brasil ainda é considerado inferior aos Estados Unidos e Reino Unido, em razão de fatores históricos, culturais e da responsabilidade das instituições no processo de educação financeira (SAVOIA, SAITO \& SANTANA, 2007, p. 1123). Entretanto, as propostas de educação financeira Brasil e dos Estados Unidos são consideradas semelhantes (SARAIVA, 2017).

De acordo com o Serviço de Proteção ao Crédito (SPC Brasil) e a Confederação Nacional de Dirigentes Lojistas (CNDL), o número de pessoas com dívidas em atraso no Brasil foi de 62,7 milhões no

\footnotetext{
"Doutor, Mestre e Bacharel em Ciências Contábeis pela Faculdade de Economia, Administração e Contabilidade da Universidade de São Paulo. Professor da Universidade Federal de São Paulo. E-mail: samir.sayed@unifesp.br

" Universidade Federal de São Paulo.
} 
primeiro trimestre de 2019 , comparado com ao mesmo período do ano anterior houve uma alta de mais de $2 \%$; tal número representa mais de $40 \%$ da população adulta brasileira (SPC, 2019).

Buaes (2015) aponta que os cartões de crédito e as diversas linhas de crédito são os produtos do mercado financeiro que mais facilmente são acessados pela população. De acordo com informações da Pesquisa de Endividamento e Inadimplência do Consumidor (PEIC) são estes produtos que também levam a população a um elevado nível de endividamento, sendo que o percentual de famílias brasileiras que relataram ter dívidas entre cheque pré-datado, cartão de crédito, cheque especial, carnê de loja, empréstimo pessoal, prestação de carro e seguro chegou a 61,5\% em fevereiro de 2019 (SPC, 2019).

Nota-se, portanto, que apesar do crédito ser uma ferramenta econômica capaz de permitir o adiantamento do poder de compra trazendo benefícios para o consumidor, as diversas opções de crédito disponíveis na atualidade vem conduzindo a economia do país a registrar índices preocupantes em relação ao endividamento familiar, com o devedor não conseguindo arcar com suas obrigações. Dado esse contexto, Boligon, Bortoluzzi, Hollveg e Medeiros (2015) apontam que é de vital importância que os indivíduos realizem o planejamento orçamentário e adquiram uma educação financeira.

Tais dados mostram que houve mais avanços alcançados em termos de ampliação do acesso a serviços financeiros (medidos pela capilaridade dos pontos de atendimento, relacionamento bancário, custo e acesso ao crédito, em especial, pela população de baixa renda), do que em educação financeira (medida por indicadores como níveis de endividamento, inadimplência e depósitos per capita), tornando importante que haja avanços nesta dimensão (RCF, 2018).

Além do mais, segundo o levantamento do Serviço de Proteção ao Crédito (SPC Brasil) e da Confederação Nacional de Dirigentes Lojistas (CNDL), feito em parceria com o Banco Central do Brasil $(\mathrm{BCB})$, o número de consumidores que ainda não controlam suas finanças, com um acompanhamento e análise de seus ganhos e gastos por meio de um orçamento é de $36 \%$ dos brasileiros (SPC, 2019).

Em relação às famílias norte-americanas, aproximadamente $80 \%$ têm dívidas, porém diferentemente da realidade brasileira, em que as dívidas correspondem principalmente aos cartões de crédito e cheque especial, nos Estados Unidos os passivos mais relevantes são decorrentes de financiamentos estudantis, especialmente os universitários e hipotecas. Na sequência aparecem as dívidas de cartão de crédito que aumentaram sensivelmente na última década. Excluindo-se as dívidas estudantis e hipotecas, aproximadamente $50 \%$ dos lares americanos comprometem suas rendas, com dívidas de crédito, como cartões e empréstimos bancários. Em relação aos montantes, os passivos totais das famílias norteamericanas somam U\$ $\$ 14,1$ trilhões, sendo desse montante US\$ 9,6 trilhões de hipotecas e US\$1,5 trilhão de financiamentos estudantis (US CENSUS BUREAU, 2018).

No tocante aos investimentos das pessoas, ainda é baixa a quantidade de pessoas físicas que acessam a Bolsa de Valores e adquirem ações no Brasil. Dados de 2019 apontam que aproximadamente 1,5 milhão de pessoas investem no mercado de ações, isto é, aproximadamente $1 \%$ da população total (B3, 2019). Esse fato pode ser explicado por uma falta de cultura de poupança de longo prazo, bem como por falta de planejamento financeiro ou renda suficiente para tal ação (SALEH \& SALEH, 2013). Apesar dos rendimentos diminutos, a poupança ainda é o investimento favorito dos brasileiros: em pesquisa do SPC (2019), 65\% utilizam essa forma ao poupar seu dinheiro.

Diferentemente do cenário nacional, aproximadamente $14 \%$ das famílias norte-americanas investem diretamente em ações e $52 \%$ em fundos de investimentos ou planos de aposentadoria (STATISTA, 2017).

No Brasil a educação financeira ainda não se faz presente de maneira obrigatória nos bancos escolares, diferentemente dos Estados Unidos, em que uma parte relevante dos estados tem essa disciplina como carga obrigatória para crianças e adolescentes (SARAIVA, 2017).

Como não faz parte da formação formal dos brasileiros, os mesmos devem (ou deveriam) buscar tal conhecimento de maneira alternativa, recorrendo a leituras de livros, de artigos, da internet, de jornais e de outras mídias ou contando com a experiência profissional ou de vida. No caso brasileiro, o papel da mídia escrita e falada toma uma relevância maior devido à sua amplitude e facilidade de assimilação (SAVOIA, SAITO \& SANTANA, 2007, p. 1136). Nesse contexto a literatura de autoajuda financeira passou a ser um fenômeno crescente na modernidade (BORBA, 2010).

Assim sendo, o objetivo geral dessa pesquisa é comparar os livros de autoajuda financeira mais vendidos de autores brasileiros (no mercado nacional) e norte-americanos (mercado internacional) com intuito de identificar (ou não) padrão nas respectivas literaturas e possíveis explicações para os fenômenos identificados.

Dada as características econômicas dos indivíduos e dos países em questão, do conhecimento e acesso à informação financeira e do desenvolvimento do mercado de capitais, levantou-se como hipótese de que a literatura norte-americana sobre finanças pessoais é focada em investimentos financeiros, enquanto a brasileira tem predomínio sobre temas ligados ao endividamento e custos dos empréstimos.

Por fim, quando falamos na importância desse trabalho, identificamos dois pontos principais: em primeiro lugar, contribuir para o estudo de área relevante para a vida das pessoas (finanças pessoais e 
educação financeira), já que o dinheiro e sua gestão fazem parte da vida cotidiana dos indivíduos. Além disso o estudo de livros de autoajuda em finanças pessoais nos permite identificar os conteúdos implícitos nessa importante ferramenta de disseminação de conhecimento na área, já que como mencionado acima não há iniciativas específicas de educação financeira, sobretudo no Brasil; em segundo lugar, explicando os fenômenos a que propomos identificar, contribuir para o desenvolvimento de políticas públicas e privadas para ampliação da educação financeira.

\section{REFERENCIAL TEÓRICO}

\subsection{A transmissão da educação financeira: escolas e livros de autoajuda}

Quando a inserção do tema no ambiente escolar, Saito, Santana e Savoia (2007) consideram que no Brasil não há indícios de que o tema educação financeira foi agregado e desenvolvido de maneira oficial nas grades curriculares para todos os níveis de ensino. Assim, se faz necessário um progresso dessa questão também no ambiente escolar, pois permite que o jovem crie uma cultura de poupança desde de cedo e se torne consciente para lidar com a ampla variedade de instrumentos que o sistema financeiro oferece. A partir do desenvolvimento destes aspectos, o jovem pode vir a ter maior capacidade para atender melhor suas demandas pessoais. Bessa, Firmiano e Coria (2014, p. 410) apontam que os jovens demonstram uma socialização econômica insuficiente para lidarem com as exigências do mundo econômico.

Esse cenário se reflete no desempenho dos estudantes brasileiros no Programa Internacional de Avaliação de Estudantes (PISA) da OCDE de 2015, que também incluiu uma avaliação opcional da alfabetização financeira dos jovens, com intuito de verificar o letramento financeiro dos estudantes e aferir até que ponto estes têm conhecimentos e habilidades necessárias para fazer uma transição bemsucedida da escolaridade obrigatória para o ensino superior, para o emprego ou para o empreendedorismo. O Brasil apresentou desempenho em letramento financeiro bem abaixo da média dos países e economias da OCDE que participaram da avaliação: $53,3 \%$ dos estudantes brasileiros possuem desempenho abaixo do nível básico de proficiência em letramento financeiro, sendo que a média dos 10 países/economias participantes da OCDE foi 22,3\%. Segundo o mesmo estudo, na melhor das hipóteses, esses alunos estudantes conseguem identificar produtos e termos financeiros comuns, reconhecer a diferença entre necessidades e desejos, e tomar decisões simples sobre os gastos diários em contextos que eles provavelmente já experimentaram pessoalmente. E ainda apenas 2,6\% dos estudantes brasileiros apresentaram proficiência no nível máximo em comparação com 11,8\%, em média, dos estudantes dos demais países. Esses estudantes conseguem analisar produtos financeiros complexos, resolver problemas financeiros não rotineiros e demonstrar uma compreensão do cenário financeiro em termos mais amplos (OCDE, 2017). Roquete, Laureano e Botelho (2014, p. 129) apontam que os conhecimentos financeiros dos jovens podem ser explicados pelo perfil sociodemográfico do estudante, pelo background familiar, pela cultura e inclusão financeira.

Cunha e Laudares (2017) discutem também a necessidade da inserção do tema nas instituições de ensino, considerando que o mesmo pode se dar por meio da Matemática Financeira. Entretanto, para que isso aconteça transformações são necessárias, visto que os conteúdo dessa disciplina trabalhados em sala de aula têm como base a simples memorização de fórmulas, que prejudica a formação do jovem e não retrata a realidade, dificultando a aplicação de conceitos e operacionalização de cálculos aprendidos na resolução de situações reais simples. Silva, Magro, Gorla e Nakamura (2017, p. 285) argumentam que não há educação financeira efetiva entre os jovens do ensino médio, já que os mesmos não são obrigados a explicar aos pais e responsáveis em que estão gastando seus recursos financeiros, obtendo conhecimentos financeiros com pais e parentes, em ambiente de pouco diálogo sobre o assunto no seio familiar.

Pires et al. (2013) apontam que quanto mais cedo a inserção das pessoas no controle de seu dinheiro, melhor o aprendizado e decisões sobre gastos e sobre poupança.

Campbell (2006) argumenta que pessoas com educação financeira cometem erros financeiros em menor extensão; assim sendo, observa-se a necessidade de se abordar esse tema em bancos escolares.

Pereira, Cavalcante e Crocco (2019) argumentam que a proposta brasileira de educação financeira é inadequada já que é fundamental incluir o ambiente em que as decisões financeiras são tomadas, bem como o fato da qualificação financeira não poder se dar prioritariamente via transferência de conhecimento, especialmente de aconselhamento financeiro provido por indivíduos não preparados na área. Veiga et al. (2019) criaram um teste de escalas para mensurar os comportamentos em gestão financeira pessoal em que apontam que há relação negativa entre impulsividade nas compras e gestão financeira, bem como um efeito negativo na tensão financeira em indivíduos que efetuam suas gestões financeiras.

Tendo exposto a relevância e o papel que a educação financeira e as finanças pessoais desempenham, torna-se importante analisar o conteúdo dos best-sellers de finanças pessoais de autores 
brasileiros e norte-americanos. Visto que a literatura de autoajuda financeira é fenômeno crescente na hipermodernidade, no qual seu crescimento se deu com a crise do capitalismo, com inúmeras obras sendo colocadas no mercado (BORBA, 2010). De acordo com Asbohr e Ferreira (2002) a auto autoajuda é um segmento literário que objetiva basicamente ensinar o indivíduo como conduzir sua vida, relacionar-se com as pessoas, conseguir determinada posição individual, superar problemas pessoais criados pela vida moderna, buscar a felicidade sonhada através de um emprego bem-sucedido. Ou seja, os temas abordados são tão diversificados quanto os problemas enfrentados pelo leitor no seu cotidiano. Ainda, de acordo com Borba (2010) seus leitores em geral parecem buscar o apoio, auxílio ou até mesmo uma solução para seus problemas pessoais, profissionais e financeiros. No campo de finanças pessoais, uma série de iniciativas na publicação de livros de autoajuda financeira tomou corpo. Como exemplos, citamos os conhecidos Pai Rico, Pai Pobre, Casais Inteligentes Enriquecem Juntos, Os segredos da Mente Milionária, etc.. Muitos desses livros ultrapassaram milhões de unidades vendidas, sendo assim de suma importância entender sua dinâmica já que como apontado acima a educação financeira formal é inexistente ou minorada, sobretudo no Brasil.

\subsection{Comparação entre dados do Brasil e dos Estados Unidos quanto acesso ao mercado financeiro, dificuldade econômica da população e letramento financeiro (financial literacy)}

Os dados de 2016 fornecem informações importantes sobre o amplo alcance do investimento no mercado de ações nos Estados Unidos. Enquanto uma parcela relativamente pequena das famílias americanas (14\%) investem diretamente em ações individuais, a maioria (52\%) possui algum nível de investimento no mercado, notadamente através de fundos de investimentos ou na forma de contas de aposentadoria (STATISTA, 2017). Enquanto isso no Brasil aproximadamente 1,5 milhão de pessoas tem investimento diretamente na bolsa de valores, o que equivale a menos de $1 \%$ da população brasileira (B3, 2020).

Quanto ao endividamento, no Brasil $65,3 \%$ dos brasileiros estão endividados e aproximadamente $30 \%$ com alguma dívida em atraso em atraso (SPC, 2019). Já nos Estados Unidos, dados de 2016, apontam que $47,3 \%$ das famílias têm dívidas, sobretudo de hipotecas imobiliárias e crédito estudantil (STATISTA, 2017; US CENSUS BUREAU, 2018).

No Brasil a educação financeira nos bancos escolares ainda é incipiente, cabendo destacar a iniciativa governamental com apoio da iniciativa privada chamada Estratégia Nacional de Educação Financeira (ENEF) criada através do Decreto Federal 7.397/2010 com objetivo de fortalecer a cidadania ao fornecer e fomentar ações sobre educação financeira no país.

Além do mais, de acordo com o Relatório de Cidadania Financeira de 2018, o valor da média nacional do Índice de Educação Financeira (IEF) calculado no período de 2015 a 2017 é de 35, em uma escala de 0 a 100. Esse índice demonstra que os avanços alcançados em termos de sua ampliação ainda são baixos. Mesmo diante desse contexto e da necessidade do seu fomento, "a educação financeira tornou-se uma preocupação crescente em diversos países, gerando um aprofundamento nos estudos sobre o tema" (IEF, 2018).

A se destacar também que em alguns dos estados americanos, a educação financeira é adotada obrigatoriamente na grade escolar. Enquanto isso, o fato do Brasil ter passado por um longo período de instabilidades econômicas, com altas taxas de inflação acabou comprometendo a capacidade do país de realizar um planejamento econômico-financeiro de logo prazo, já que o encurtamento do horizonte de planejamento é uma característica dominante nas decisões financeiras em um processo inflacionário como meio de defesa, de modo que houve uma busca pela liquidez em defesa do poder aquisitivo e do patrimônio, que acabou influenciando a população priorizar o consumo, deixando de se criar uma cultura de poupança de longo prazo. Quando comparada a algumas realidades internacionais, a disseminação da educação financeira no Brasil se encontra em estágio de desenvolvimento inferior ao dos Estados Unidos, já que neste país existe uma grande quantidade de sites engajados nesse processo e grandes quantidades de instituições governamentais, financeiras e organizações do terceiro setor envolvidas (SAITO, SANTANA \& SAVOIA, 2007).

Saraiva (2017), ao analisar a proposta financeira dos Estados Unidos, Brasil e França a partir de uma análise nos sites de finanças pessoais dos respectivos países, conclui que a proposta de educação financeira Brasil e dos Estados Unidos são semelhantes, sendo orientadas para tornar os indivíduos individualmente responsáveis por suas escolhas e decisões financeiras, enquanto que a da França procurase mostrar de modo mais amplo o funcionamento das finanças e da economia.

\section{ASPECTOS METODOLÓGICOS}

Para atender aos objetivos do trabalho, utilizou-se a abordagem indutiva com método de procedimento comparativo de caráter qualitativo (MARCONI \& LAKATOS, 2003). Como técnica de análise de dados é utilizada a Análise de Conteúdo de Bardin (1977), conceituada como um coletivo de maneiras 
de análise de comunicações, com procedimentos sistemáticos no tocante a descrição dos conteúdos das mensagens, compreendendo o sentido, quer manifesto ou latente, explícito ou oculto, sobretudo através da codificação (CHIZZOTTI, 2006, p. 98). As etapas da análise de conteúdo segundo Bardin (1977) envolve três fases: (i) pré-análise; (ii) exploração e (iii) tratamento dos resultados, inferência e interpretação. Na préanálise há um primeiro contato com os documentos, sua seleção, formulação dos objetivos e hipóteses, bem como a criação de índices e indicadores. Na fase de exploração ocorre a definição dos codificadores e das respectivas unidades de registro ou significação. Por fim o tratamento dos resultados, inferência e interpretação há a condensação para a análise, correspondendo ao momento da intuição, da reflexão e crítica (MOZZATO \& GRZYBOVSKI, 2011, p. 735). Foi utilizado para o desenvolvimento da análise de conteúdo o software Atlas. TI especialmente nas fases de exploração e tratamento dos resultados, inferência e interpretação.

\subsection{Pré-análise dos dados}

Conforme mencionado acima a pré-análise envolve o contato e a seleção dos documentos bem como a criação de objetivos/hipóteses e índices/indicadores (BARDIN, 1977).

A amostra é composta pelos 5 livros mais vendidos de autores brasileiros no mercado nacional e pelos 5 best-sellers de autores norte-americanos nos Estados Unidos. A definição da quantidade 5 ("cinco") é discricionário dos autores em decorrência da extensão da análise.

Em primeiro lugar delimitou-se o recorte temporal utilizado, já que os livros de finanças pessoais e educação financeira tem diversas datas de lançamento e edição, bem como as bases de registro de vendas de livros que não tem informações mais antigas. Nesse sentido, foram considerados os livros vendidos no Brasil e nos Estados Unidos entre Janeiro de 2010 e Agosto de 2019, somados.

Outro ponto a destacar é a publicação de livros de autores estrangeiros no mercado brasileiro, tanto no idioma original quanto de forma traduzida. Nessa pesquisa foram usados somente os autores brasileiros no mercado nacional, já que nos rankings de livros mais vendidos também constam autores estrangeiros, conforme elucidado no quadro 1.

Quadro 1 - Mercado Brasileiro de Livros de autoajuda em Finanças Pessoais e Educação Financeira de 2010-2019

\begin{tabular}{|l|l|}
\hline Livro & Autor(es) \\
\hline Os Segredos da Mente Milionária & T. Harv Eker \\
\hline Pai Rico, Pai Pobre & Robert T. Kiyosaki \\
\hline Me Poupe & Nathalia Arcuri \\
\hline Casais Inteligentes Enriquecem Juntos & Gustavo Cerbasi \\
\hline Do Mil ao Milhão & Thiago Nigro \\
\hline
\end{tabular}

Fonte: Elaboração propria

Conforme apontado pelo quadro acima, foram desconsiderados os dois livros mais vendidos, de autores estrangeiros (Eker e Kiyosaki). Cabe apontar adicionalmente as fontes ou rankings dos livros mais vendidos no período, já que há diferentes opções nos diferentes países: no Brasil existe o ranking da revista Veja (mais antigo, porém de caráter semanal), Amazon (mais recente, de 2018) e da PublishNews (que tem dados novos e antigos contabilizados de forma semanal, mensal ou anual). Para o mercado nacional foi selecionada a plataforma da PublishNews que traz de forma sumarizada as vendas anuais. Para o mercado americano também há diversas fontes ou rankings como o do New York Times e da Amazon (bases semanais e anual para o último) e a plataforma Ranker. Para o mercado dos Estados Unidos foi selecionada a plataforma da Amazon por aglutinar os dados anualmente. Em relação aos rankings, ressaltase que os livros de finanças pessoais podem se enquadrar em diferentes categorias já que não existe uma classificação específica. Assim encontramos as obras ou classificadas como autoajuda (Amazon - Estados Unidos) ou negócios (PublishNews - Brasil). Os quadros 2 e 3 abaixo elucidam os livros selecionados nas respectivas amostras: 
Quadro 2 - Mercado Brasileiro de Livros autoajuda em Finanças Pessoais e Educação Financeira de 20102019

\begin{tabular}{|l|l|}
\hline Livro & Autor(es) \\
\hline Me Poupe & Nathalia Arcuri \\
\hline Casais Inteligentes Enriquecem Juntos & Gustavo Cerbasi \\
\hline Do Mil ao Milhão & Thiago Nigro \\
\hline Desperte o Milionário que Há em Você & Carlos Wizard Martins \\
\hline Adeus Aposentadoria & Gustavo Cerbasi \\
\hline
\end{tabular}

Fonte: Elaboração própria

Quadro 3 - Mercado Norte-Americano de Livros de Finanças Pessoais e Educação Financeira de 2010-2019

\begin{tabular}{|l|l|}
\hline Livro & Autor(es) \\
\hline The Total Money Makeover & Dave Ramsey \\
\hline Rich Dad Poor Dad & Robert T. Kiyosaki \\
\hline I Will Teach You to Be Rich & Ramit Sethi \\
\hline The Intelligent Investor & Benjamim Graham \\
\hline Think and Grow Rich & Napoleon Hill \\
\hline
\end{tabular}

Fonte: Elaboração própria

Quanto ao contato e seleção, foram adquiridos todos os livros em formato digital a fim de que fossem trabalhados no software Atlas Ti.

Quanto à formulação de objetivos/hipóteses, dada a importância do livro como elemento formativo no campo da educação financeira e das finanças pessoais, bem como o seu alcance, notadamente pela grande quantidade de livros vendidos, o objetivo é entender as similaridades e diferenças nos best-sellers selecionados nos respectivos países, apoiando-se nas categorias descritas pela Certified Financial Planner (CFP) do Financial Planning Standards Board Ltd.(FPSB) sobre os pontos de um plano financeiro: (i) gestão de ativos e investimentos; (ii) planejamento financeiro; (iii) planejamento de aposentadoria; (iv) planejamento fiscal; (v) planejamento de riscos e seguros e (vi) planejamento sucessório. Escolheu-se a metodologia do CFP por ser uma estrutura conceitual completa no que tange ao planejamento financeiro pessoal e familiar. Nesse sentido buscou-se, em primeiro lugar, identificar padrão ou foco em algum (ns) código (s) nas respectivas literaturas.

Quanto às hipóteses, espera-se que a literatura de autores norte-americanos seja mais focada na questão de gestão de ativos e investimentos, gestão de aposentadoria e assuntos correlatos, especialmente na área de investimentos e/ou aposentadoria, com menor destaque no que tange ao planejamento financeiro, sobretudo na questão de controle de despesas e passivos. Para a literatura de autores brasileiros espera-se que o foco esteja em planejamento financeiro, principalmente no controle de gastos e diminuição de dívidas, com menor destaque para a questão de ativos e investimentos. Essas hipóteses são apoiadas nas diferenças econômicas e sociais dos dois países, no desenvolvimento e acesso ao mercado de capitais e no financial literacy de sua população.

\subsection{Exploração}

Foram efetuadas duas leituras de cada obra: a primeira focando a capa e título, o índice e superficialmente o corpo do livro e a segunda, leitura mais atenta, focando na criação da codificação e exploração, baseando-se na estrutura conceitual do Planejamento Financeiro Pessoal (CFP - Certified Financial Planner) do Financial Planning Standards Board Ltd.(FPSB) que contém seis pontos de um planejamento financeiro pessoal completo: (i) planejamento financeiro; (ii) gestão de ativos e investimentos; (iii) planejamento de aposentadoria; (iv) planejamento fiscal; (v) planejamento de riscos e seguros e (vi) planejamento sucessório (PLANEJAR, 2019).

Em relação ao item (i) planejamento financeiro, abordam-se "assuntos que sustentam esse processo: (a) a análise da gestão financeira de um indivíduo ou uma família; (b) o conhecimento de fundamentos de 
economia, finanças e estatísticas e (c) a aplicação e avaliação de métodos de análise de investimentos" (PLANEJAR, 2019, p. 5).

A (ii) gestão de ativos e investimentos é baseada em instrumentos de renda fixa, renda variável e de derivativos, contemplando também os investimentos no exterior (do ponto de vista do investidor residente no Brasil) e os investimentos imobiliários (PLANEJAR, 2019, p. 14).

$\mathrm{O}$ (iii) planejamento de aposentadoria refere-se ao dimensionamento do capital necessário para gerar renda na aposentadoria, bem como o orçamento estimado, a sobrevida, os objetivos de sucessão (se houver) e o retorno esperado da carteira de ativos do indivíduo (PLANEJAR, 2019, p. 27).

$O$ (iv) planejamento fiscal aborda a "interferência de impostos e tributos sobre as diversas atividades exercidas pelas pessoas físicas e jurídicas, assim como suas repercussões sobre suas posições financeiras e o resultado final de transações financeiras em geral" (PLANEJAR, 2019, p. 21).

$\mathrm{O}$ (v) planejamento de riscos e seguros reforça a importância dos seguros em relação ao bem-estar e segurança patrimonial pessoal, focando no entendimento da cobertura dos diversos tipos de seguros, os aspectos legais, tributários, sobretudo nos seguros de bens e pessoas, tais como residência, veículos, vida, empresarial, de responsabilidade, rural, acidentes pessoais e saúde (PLANEJAR, 2019, p. 18).

Por fim, o (vi) planejamento sucessório estuda as decisões envolvidas para preparar e entender as alternativas na transmissão de bens, em caso de morte. Nessa direção, objetiva entender as dinâmicas e custos tributários, bem como os aspectos societários e regulatórios envolvidos nas questões tanto de bens móveis quanto imóveis (PLANEJAR, 2019, p. 24).

A fim de alcançar os objetivos da pesquisa, apresentaremos a seguir a etapa de tratamento dos dados, focando na contagem ou frequência de palavras e expressões e por fim na análise textual dos capítulos dos livros.

\section{RESULTADOS}

Apresenta-se os resultados em duas frentes: (4.1) a etapa dos tratamentos dos dados e (4.2) da inferência e interpretação. Na primeira (4.1) são feitas duas análises: (4.1.1) análise da contagem e frequência de palavras e expressões e (4.1.2) a análise e codificação textual dos capítulos dos livros. Na segunda (4.2) busca-se relacionar os resultados e interpretá-los a luz das condições econômicas e sociais das duas nações bem como no financial literacy de suas populações.

\subsection{Tratamento dos dados}

\subsubsection{Análise de contagem e frequência de palavras e expressões}

Muito utilizado na análise de conteúdo a contagem e a frequência de palavras e expressões pode indicar significados e tendências das obras analisadas (BARDIN, 1977).

Nesse sentido, apresenta-se a nuvem de palavras que tem como finalidade oferecer subsídios para entender os termos mais importantes nos dados. Abaixo a nuvem de palavras para os livros de autores brasileiros obtidos através do Word Cloud do software Atlas Ti:

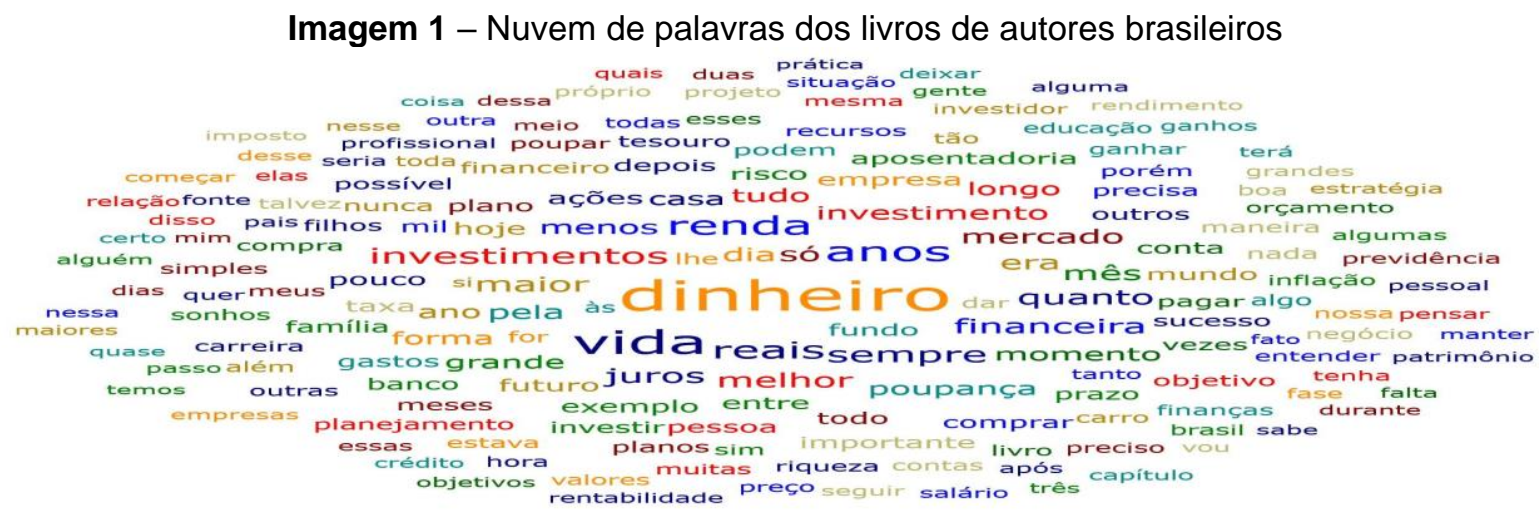

Fonte: Word Cloud do software Atlas Ti

Percebe-se na análise da imagem que como de se esperar a palavra "dinheiro" assume posição central com 915 aparições. Quando inseridas nas codificações utilizadas, verifica-se que há presença marcante de termos que vinculam à gestão de ativos e investimentos, especialmente termos que circundam "dinheiro", como "investimentos", "juros", "banco", "anos", "poupança".

Também, verificou-se a presença importante da codificação sobre planejamento financeiro, como nos 
termos "gastos", "planejamento", "planos" e também outras como planejamento de aposentadoria e sucessório, respectivamente.

Agora é elucidada a nuvem de palavras dos livros dos autores norte-americanos:

Imagem 2 - Nuvem de palavras dos livros de autores norte-americanos

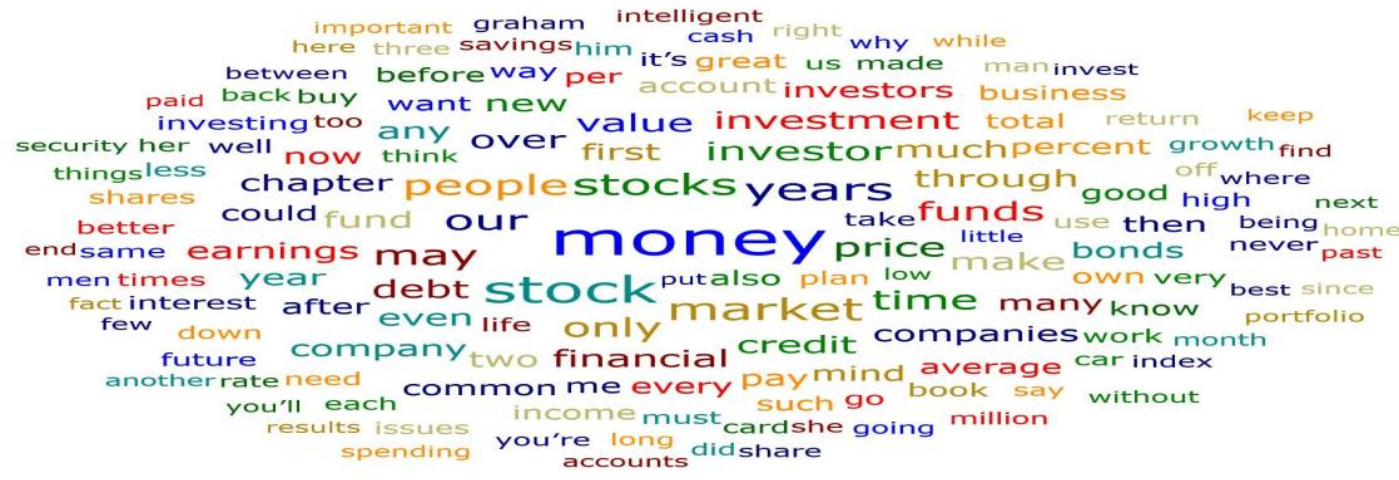

Fonte: Word Cloud do software Atlas Ti

Percebe-se que o foco das palavras correspondem ao código gestão de ativos e investimentos que são verificadas nas palavras maiores e mais centralizadas, como por exemplo, "stock (s) ", "market", "price", "investor", "investments".

Verifica-se com a análise das duas nuvens de palavras que nos autores brasileiros há uma divisão no foco das publicações em planejamento financeiro e gestão de ativos e investimentos, enquanto que nas obras dos autores norte-americanos o foco principal e sem concorrentes reside na codificação gestão de ativos e investimentos.

Com intuito de finalizarmos os aspectos descritivos das literaturas, é efetuada abaixo a análise textual com as respectivas codificações nos conteúdos das obras analisadas neste estudo.

\subsubsection{Análise de textual dos conteúdos dos capítulos das obras selecionadas}

Especificamente, nesse ponto da análise são buscadas frases e parágrafos que reflitam as codificações utilizadas no trabalho. Para isso, a tabela 1 é apresentada e discutida a seguir:

Tabela 1 - Frequência e codificação das obras completas de livros de autores norte-americanos de finanças pessoais

\begin{tabular}{l|c|c|c|c|c|c}
\hline Código/Livro & $\begin{array}{c}\text { The Total } \\
\text { Money } \\
\text { Makeover }\end{array}$ & $\begin{array}{c}\text { Rich Dad } \\
\text { Poor Dad }\end{array}$ & $\begin{array}{c}\text { I Will Teach } \\
\text { You to Be Rich }\end{array}$ & $\begin{array}{c}\text { The Intelligent } \\
\text { Investor }\end{array}$ & $\begin{array}{c}\text { Think and } \\
\text { Grow Rich }\end{array}$ & Total \\
\hline $\begin{array}{l}\text { Planejamento } \\
\text { Financeiro }\end{array}$ & 223 & 77 & 42 & 12 & 23 & 377 \\
\hline $\begin{array}{l}\text { Gestão de Ativos e } \\
\text { Investimentos }\end{array}$ & 453 & 81 & 97 & 255 & 124 & 1.010 \\
\hline $\begin{array}{l}\text { Planejamento de } \\
\text { Aposentadoria }\end{array}$ & 37 & 12 & 21 & 11 & 18 & 99 \\
\hline $\begin{array}{l}\text { Planejamento } \\
\text { Fiscal }\end{array}$ & 23 & 31 & 39 & 9 & 15 & 117 \\
\hline $\begin{array}{l}\text { Planejamento de } \\
\text { Riscos e Seguros }\end{array}$ & 19 & 17 & 3 & 5 & 8 & 52 \\
\hline $\begin{array}{l}\text { Planejamento } \\
\text { Sucessório }\end{array}$ & 13 & 25 & 14 & 3 & 4 & 59 \\
\hline Total & 768 & 243 & 216 & 295 & 192 & 1.714 \\
\hline
\end{tabular}

Fonte: Elaboração própria, segundo análise no software Atlas Ti 
Ao analisar-se as frequências das codificações nos livros completos, verifica-se que na literatura de autores norte-americanos o foco das aparições se dá na rubrica gestão de ativos e investimentos com 1.010 menções (parágrafos ou frases) o que corresponde a $58,63 \%$ do total das codificações identificadas.

Em relação às codificações sobre planejamento financeiro constam 377 citações nas 5 obras norteamericanas, isto é, $22 \%$ do total dos itens codificados. No tocante ao código planejamento fiscal foram encontradas 117 citações, ou $6,83 \%$ do total.

A seguir trazemos exemplos das referidas codificações nos livros americanos:

Quadro 4 - Exemplos de citações codificadas em Gestão de Ativos e Investimentos, Planejamento Financeiro, Planejamento Fiscal, Planejamento de Aposentadoria, Planejamento de Riscos e Planejamento Sucessório nos livros americanos

\begin{tabular}{|c|c|c|}
\hline Código & Livro & Citação \\
\hline \multirow[t]{3}{*}{$\begin{array}{l}\text { Gestão de Ativos e } \\
\text { Investimentos }\end{array}$} & $\begin{array}{l}\text { The Total Money } \\
\text { Makeover }\end{array}$ & $\begin{array}{l}\text { "In our culture we worship the complicated and the sophisticated. } \\
\text { (...) I have met with thousands of millionaires, and in almost every } \\
\text { case they keep their investing and money philosophies very } \\
\text { uncomplicated. Just this week I was discussing investing and } \\
\text { business structure with a friend of mine whose net worth is over } \\
\text { twenty million dollars, and his words to me were, "I always keep it } \\
\text { simple and clean"." (Ramsey, 2009, p. 15). }\end{array}$ \\
\hline & $\begin{array}{l}\text { The Intelligent } \\
\text { Investor }\end{array}$ & $\begin{array}{l}\text { "To invest intelligently in securities one should be fore- armed with } \\
\text { an adequate knowledge of how the various types of bonds and } \\
\text { stocks have actually behaved under varying condi- tions-some of } \\
\text { which, at least, one is likely to meet again in one's own experience. } \\
\text { No statement is more true and better applicable to Wall Street than } \\
\text { the famous warning of Santayana: "Those who do not remember } \\
\text { the past are condemned to repeat i2t."' (Graham, 2003, p. 1). }\end{array}$ \\
\hline & $\begin{array}{l}\text { Think and Grow } \\
\text { Rich }\end{array}$ & $\begin{array}{l}\text { "The clerk was taking a big chance by staking his entire life's } \\
\text { savings on a mere scrap of paper and an old kettle! He never } \\
\text { dreamed his investment would start a kettle to overflowing with gold } \\
\text { that would surpass the miraculous performance of Aladdin's lamp }{ }^{3} . " \\
\text { (Hill, 2019, p. 95). }\end{array}$ \\
\hline $\begin{array}{l}\text { Planejamento } \\
\text { Financeiro }\end{array}$ & $\begin{array}{l}\text { The Total Money } \\
\text { Makeover: }\end{array}$ & $\begin{array}{l}\text { "Myth: I don't have time to work on a budget (...). Truth: You don't } \\
\text { have time not to4." (Ramsey, 2009, p. 30). }\end{array}$ \\
\hline $\begin{array}{l}\text { Planejamento } \\
\text { Fiscal }\end{array}$ & $\begin{array}{l}\text { I Will Teach You } \\
\text { to Be Rich }\end{array}$ & $\begin{array}{l}\text { "Listen to me: You pay taxes only if you make money. If you are } \\
\text { paying } 30 \text { percent in taxes on something, it means you made } 70 \\
\text { percent elsewhere, so do not freak out about taxes. Plus, it's your } \\
\text { damned civic duty5." (Sethi, 2009, p. 117). }\end{array}$ \\
\hline
\end{tabular}

\footnotetext{
${ }^{1}$ Em nossa cultura adoramos os complicados e sofisticados. (...) Eu me encontrei com milhares de milionários, e os mesmos mantém suas filosofias de investimento e do dinheiro muito descomplicadas. Apenas esta semana eu estava discutindo o investimento e a estrutura de negócio com um amigo meu, cujo o valor líquido é de 20 milhões de dólares, e suas palavras a mim eram, "eu mantenho-o sempre simples e descomplicado".

2 Para investir de forma inteligente em títulos deve-se ter conhecimento adequado de como os vários tipos de títulos e ações têm realmente se comportado em condições variáveis, alguns dos quais, pelo menos, é provável que aconteçam novamente. Nenhuma declaração é mais verdadeira e mais aplicável a Wall Street do que o famoso aviso de Santayana: Aqueles que não se lembram do passado estão condenados a repeti-lo.

${ }^{3}$ O funcionário estava tendo uma grande chance, apostando as economias de toda a sua vida em um mero pedaço de papel e uma chaleira velha! Ele nunca sonhou que seu investimento iria iniciar em uma chaleira para transbordar de ouro que superaria o desempenho milagroso da lâmpada de Aladdin.

${ }^{4}$ Mito: Eu não tenho tempo para trabalhar em um orçamento (...).

Verdade: Você não tem tempo para não.

${ }^{5}$ Ouça-me: você paga impostos somente se você ganhar dinheiro. Se você está pagando 30 por cento em impostos sobre algo, isso significa que você fez 70 por cento em outro lugar, por isso não surtar sobre os impostos. Além disso, é o seu dever cívico maldito.
} 


\begin{tabular}{|c|c|c|}
\hline & & Continuação \\
\hline Código & Livro & Citação \\
\hline $\begin{array}{l}\text { Planejamento de } \\
\text { Aposentadoria }\end{array}$ & $\begin{array}{l}\text { The Total Money } \\
\text { Makeover: }\end{array}$ & $\begin{array}{l}\text { "Invest } 15 \text { Percent of Your Income in Retirement Those of you } \\
\text { concerned about retirement are relieved we have finally gotten to } \\
\text { this step. Those who have been living in denial are wondering what } \\
\text { all the fuss is about. Baby Step Four is time to get really serious } \\
\text { about your wealth building. Remember, when you reach this step } \\
\text { you don't have any payments but a house payment, and you have } \\
\text { three to six months' worth of expenses in savings, which is } \\
\text { thousands of dollars. With only one payment, it should be easy to } \\
\text { invest heavily. Even with a below-average income, you can ensure } \\
\text { your golden years will have dignity. Before this step, you have } \\
\text { ceased or have never started investing, and now you have to really } \\
\text { pour on the coal6." (Ramsey, 2009, p. 476). }\end{array}$ \\
\hline $\begin{array}{l}\text { Planejamento de } \\
\text { Riscos }\end{array}$ & $\begin{array}{l}\text { Rich Dad Poor } \\
\text { Dad }\end{array}$ & $\begin{array}{l}\text { "He called to complain that a mortgage company was counting his } \\
\text { cosigning for his mom's car against him as a debt even though she } \\
\text { had insurance that would pay the loan if she died. Of course, they } \\
\text { count it; it is a debt you are liable for! The mortgage company isn't } \\
\text { worrying about her dying; they are worried about her not paying, } \\
\text { which would require him to make her car payments and then } \\
\text { possibly not be able to pay his mortgage." (Kiyosaki \& Lechter, } \\
2000, \text { p. 135). }\end{array}$ \\
\hline $\begin{array}{l}\text { Planejamento } \\
\text { Sucessório }\end{array}$ & $\begin{array}{l}\text { The Total Money } \\
\text { Makeover: }\end{array}$ & $\begin{array}{l}\text { "Myth: My divorce decree says my spouse has to pay the debt, so I } \\
\text { don't. ruth: Divorce decrees do not have the power to take your } \\
\text { name off credit cards and mortgages, so if your spouse doesn't } \\
\text { pay, be ready to. You still owe the debt'." (Ramsey, 2009, p. 762). }\end{array}$ \\
\hline
\end{tabular}

Fonte: Elaboração própria, segundo análise no software Atlas Ti

Em relação aos conteúdos das obras nacionais a tabela 2 evidencia as obras e as frequências das respectivas codificações utilizadas no estudo:

Tabela 2 - Frequência e codificação das obras completas de livros de autores brasileiros de finanças pessoais

\begin{tabular}{l|c|c|c|c|c|c} 
Código/Livro & Me Poupe & $\begin{array}{c}\text { Casais } \\
\text { Inteligentes } \\
\text { Enriquecem } \\
\text { Juntos }\end{array}$ & $\begin{array}{c}\text { Do Mil ao } \\
\text { Milhão }\end{array}$ & $\begin{array}{c}\text { Desperte o } \\
\text { Milionário } \\
\text { que Há em } \\
\text { Você }\end{array}$ & $\begin{array}{c}\text { Adeus } \\
\text { Aposentadoria }\end{array}$ & Total \\
\hline $\begin{array}{l}\text { Planejamento } \\
\text { Financeiro }\end{array}$ & 104 & 192 & 121 & 38 & 38 & 493 \\
\hline $\begin{array}{l}\text { Gestão de Ativos } \\
\text { e Investimentos }\end{array}$ & 90 & 103 & 271 & 72 & 91 & 627 \\
\hline $\begin{array}{l}\text { Planejamento de } \\
\text { Aposentadoria }\end{array}$ & 27 & 37 & 11 & 1 & 94 & 170 \\
\hline
\end{tabular}

\footnotetext{
${ }^{6}$ Investir 15 por cento de sua renda na aposentadoria. Aqueles de vocês preocupados com a aposentadoria estão aliviados que finalmente chegamos a este passo. Aqueles que têm vivido na negação estão querendo saber sobre o que é todo o alarido. Passinho Quatro é hora de ficar muito sério sobre a sua construção de riqueza. Com apenas um pagamento, deve ser fácil investir pesadamente. Mesmo com uma renda abaixo da média, você pode garantir que seus anos dourados terão dignidade. Antes desta etapa, você cessou ou nunca começou a investir, e agora você tem que realmente derramar sobre as brasas.

${ }^{7}$ Ele ligou para reclamar que uma empresa hipotecária estava cobrando a consignação do carro de sua mãe contra ele como uma dívida, embora ela tivesse um seguro que pagaria o empréstimo se ela morresse. Claro que eles cobram; é uma dívida que você é responsável! A empresa hipotecária não está se preocupando com a morte dela; eles estão preocupados com ela não pagar, o que exigiria que ele faça seus pagamentos de carro e, em seguida, possivelmente não ser capaz de pagar sua hipoteca.

${ }^{8}$ Mito: Meu contrato de divórcio diz que meu cônjuge tem que pagar a dívida, não eu. Verdade: Os contratos de divórcio não têm o poder tirar fora seu nome dos cartões de crédito e das hipotecas, assim que se seu cônjuge não paga, esteja pronto a isso. Você ainda deve a dívida.
} 


\begin{tabular}{l|c|c|c|c|c|c}
\hline Código/Livro & Me Poupe & $\begin{array}{c}\text { Casais } \\
\text { Inteligentes } \\
\text { Enriquecem } \\
\text { Juntos }\end{array}$ & $\begin{array}{c}\text { Do Mil ao } \\
\text { Milhão }\end{array}$ & $\begin{array}{c}\text { Desperte o } \\
\text { Milionário } \\
\text { que Há em } \\
\text { Você }\end{array}$ & $\begin{array}{c}\text { Adeus } \\
\text { Aposentadoria }\end{array}$ & Total \\
\hline $\begin{array}{l}\text { Planejamento } \\
\text { Fiscal }\end{array}$ & 2 & 5 & 1 & 7 & 8 & 23 \\
\hline $\begin{array}{l}\text { Planejamento de } \\
\text { Riscos e } \\
\text { Seguros }\end{array}$ & 2 & 3 & 1 & 0 & 6 & 12 \\
\hline $\begin{array}{l}\text { Planejamento } \\
\text { Sucessório }\end{array}$ & 0 & 12 & 0 & 0 & 5 & 17 \\
\hline Total & 225 & 352 & 405 & 118 & 242 & 1342 \\
\hline
\end{tabular}

Fonte: Elaboração própria, segundo análise no software Atlas Ti

Percebe-se, na literatura de autores brasileiros, a predominância de duas codificações: em primeiro, gestão de ativos e investimentos com 627 aparições (46,72\% do total) e logo em sequência tem-se planejamento financeiro com 493 aparições (36,73\% do total). Verifica-se, pois, que aproximadamente $84,45 \%$ das citações encontradas correspondem às duas codificações supracitadas somadas.

Em relação às demais codificações, percebe-se que o terceiro com maior número de aparições nas obras de autores nacionais é o "planejamento de aposentadoria" com 170 no total ou 12,67\%. Apesar de obra dedicada ao tema "Adeus Aposentadoria" com 90 citações, também se percebe a presença desta codificação nas demais obras (80 citações).

As demais codificações ("planejamento fiscal", "planejamento de riscos e seguros" e "planejamento sucessório") correspondem juntas a aproximadamente $3,87 \%$ do total, demonstrando que tais não são itens de foco na literatura de autores nacionais.

A seguir há exemplos das referidas codificações e das demais, nos livros brasileiros:

Quadro 5 - Exemplos de citações codificadas em Gestão de Ativos e Investimentos, Planejamento Financeiro, Planejamento Fiscal, Planejamento de Aposentadoria, Planejamento de Riscos e Planejamento Sucessório nos livros brasileiros

\begin{tabular}{|l|l|l|}
\hline Código & Livros & Citações \\
\hline $\begin{array}{l}\text { Gestão de Ativos e } \\
\text { Investimentos }\end{array}$ & $\begin{array}{l}\text { Casais } \\
\text { Inteligentes } \\
\text { Enriquecem } \\
\text { Juntos }\end{array}$ & $\begin{array}{l}\text { "Em um relacionamento a dois, fica difícil discutir sobre } \\
\text { investimentos de risco, como ações e moeda estrangeira, pois cada } \\
\text { cabeça tem um diferente nível de aversão ao risco" (Cerbasi, 2004, } \\
\text { p. 32). }\end{array}$ \\
\cline { 2 - 3 } Me Poupe & $\begin{array}{l}\text { "A maioria dos brasileiros não tem nenhum dinheiro trabalhando } \\
\text { para eles. Poucos conseguem fazer sobrar alguma coisa no fim do } \\
\text { mês. Muitos se endividam para pagar as contas básicas" (Arcuri, } \\
\text { 2018, p. 98). }\end{array}$ \\
\cline { 2 - 3 } & Do Mil ao Milhão \\
\cline { 2 - 3 } & $\begin{array}{l}\text { "Lembro, porém, que devemos diversificar, e não pulverizar o nosso } \\
\text { dinheiro. Se diversificamos demais, passamos a ter uma carteira } \\
\text { muito complexa e com pouca efetividade. Acabamos tendo tantos } \\
\text { ativos em carteira que a tomada de decisão, tanto para comprar } \\
\text { quanto para vender, acaba se atrasando. Isso nos prejudica } \\
\text { bastante. Por isso, recomendo que uma boa carteira de } \\
\text { investimentos tenha no máximo dez ativos. Assim, cada um } \\
\text { representaria 10\% da carteira, e o risco estaria muito bem } \\
\text { diversificado" (Nigro, 2018, p. 95). }\end{array}$ \\
\hline
\end{tabular}




\begin{tabular}{|c|c|c|}
\hline Código & Livros & Citações \\
\hline \multirow[t]{2}{*}{$\begin{array}{l}\text { Gestão de Ativos e } \\
\text { Investimentos }\end{array}$} & \begin{tabular}{l|} 
Desperte o \\
Milionário que Há \\
em Você
\end{tabular} & $\begin{array}{l}\text { "Para acumular } 1 \text { milhão de reais, você precisa primeiro acumular } \\
100 \text { mil reais. Para acumular } 100 \text { mil reais, você precisa primeiro } \\
\text { acumular } 10 \text { mil reais. Para acumular } 10 \text { mil reais você precisa } \\
\text { primeiro acumular } 1.000 \text { reais. } \\
\text { Se você não seguir esse modelo, jamais será um milionário! Todos } \\
\text { os que venceram e fizeram fortuna submeteram-se a uma } \\
\text { metodologia financeira, aplicada com um alto grau de disciplina e } \\
\text { de autocontrole. Eles aprenderam que mais importante que se } \\
\text { matar de trabalhar é criar uma condição em que o dinheiro trabalhe } \\
\text { por você. Descobriram também que nunca é tarde demais para } \\
\text { começar a aplicar essas regras em seu dia a dia." (Martins, 2012, p. } \\
\text { 47). }\end{array}$ \\
\hline & $\begin{array}{l}\text { Adeus } \\
\text { Aposentadoria }\end{array}$ & $\begin{array}{l}\text { "Investimentos. Investir, nessa fase da vida, é acompanhar o } \\
\text { desempenho daqueles que prestam o serviço de decidir a aplicação } \\
\text { de seus recursos. Estude continuamente sobre esse tema e afaste- } \\
\text { se da rotina, mas não do acompanhamento dos resultados. } \\
\text { Redobre seus cuidados com os efeitos inflacionários. Dessa fase } \\
\text { em diante, seus investimentos estarão divididos em aplicações de } \\
\text { renda fixa (incluindo uma parcela com alta liquidez para } \\
\text { emergências e cuidados com a sucessão patrimonial) e recursos } \\
\text { em renda variável sendo trabalhados com atitude empreendedora" } \\
\text { (Cerbasi, 2014, p. 25). }\end{array}$ \\
\hline \multirow[t]{4}{*}{$\begin{array}{l}\text { Planejamento } \\
\text { Financeiros }\end{array}$} & \begin{tabular}{|l|} 
Casais \\
Inteligentes \\
Enriquecem \\
Juntos
\end{tabular} & $\begin{array}{l}\text { Será tão difícil aprender planejamento financeiro? Na verdade, não. } \\
\text { "O planejamento financeiro familiar - que também chamo de plano } \\
\text { de independência financeira - não requer cálculos complexos nem } \\
\text { grande habilidade com números ou calculadoras. Boa parte das } \\
\text { ferramentas necessárias ao planejamento pode ser obtida sem } \\
\text { custo e está pronta para ser usada em casa1. Certamente, aqueles } \\
\text { sem aptidão nem afinidade com números sentirão maior } \\
\text { dificuldade, mas garanto que será apenas no começo. Traçar um } \\
\text { plano com objetivos claros, segui-lo e acompanhar as metas } \\
\text { aproximando-se é algo muito prazeroso. Muitos obstáculos de curto } \\
\text { prazo são relevados quando se perseguem objetivos maiores de } \\
\text { longo prazo" (Cerbasi, 2004, p. 14). }\end{array}$ \\
\hline & Me Poupe & $\begin{array}{l}\text { "É comum a ocorrência de sintomas como endividamento } \\
\text { excessivo, descontrole financeiro e total desconhecimento de } \\
\text { saídas eficazes para o problema" (Arcuri, 2018, p. 40). }\end{array}$ \\
\hline & Do Mil ao Milhão & $\begin{array}{l}\text { "A realidade é que quem só possui dívidas não consegue adotar } \\
\text { uma estratégia de crédito consciente. (...) } \\
\text { O próprio sistema financeiro oferece parte da solução, com feirões } \\
\text { para renegociação de dívidas e portabilidade de contratos. Ao } \\
\text { mesmo tempo devem ser buscadas maneiras de aumentar a renda, } \\
\text { como batalhar por uma promoção, buscar um serviço extra nas } \\
\text { horas que antes seriam de folga ou partir para o } \\
\text { empreendedorismo, mesmo que de forma limitada." (Nigro, 2018, p. } \\
\text { 17). }\end{array}$ \\
\hline & $\begin{array}{l}\text { Desperte o } \\
\text { Milionário que Há } \\
\text { em Você }\end{array}$ & $\begin{array}{l}\text { "Não importa quão desfavorável seja sua condição atual, jamais a } \\
\text { aceite como permanente. O melhor a fazer é conscientizar-se de } \\
\text { que algo precisa mudar na forma de administrar seu dinheiro. } \\
\text { Primeiro analise, como eu disse anteriormente, qual é a fonte } \\
\text { causadora de suas dívidas, e depois se comprometa a adotar um } \\
\text { modelo mais saudável e racional na administração das próprias } \\
\text { finanças. Falarei mais sobre isso adiante" (Martins, 2012, p. 64). }\end{array}$ \\
\hline
\end{tabular}




\begin{tabular}{|l|l|l|}
\hline Código & Livros & Citações \\
\hline $\begin{array}{l}\text { Planejamento } \\
\text { Financeiros }\end{array}$ & $\begin{array}{l}\text { Adeus } \\
\text { Aposentadoria }\end{array}$ & $\begin{array}{l}\text { "A sedução do consumo não é uma fraqueza individual, e sim um } \\
\text { vício social. Quem consome além de seus limites está, em geral, } \\
\text { sendo estimulado pelo reconhecimento que esse consumo traz." } \\
\text { (Cerbasi, 2014, p. 38). }\end{array}$ \\
\hline $\begin{array}{l}\text { Planejamento de } \\
\text { Aposentadoria }\end{array}$ & $\begin{array}{l}\text { Casais } \\
\text { Inteligentes } \\
\text { Enriquecem } \\
\text { Juntos }\end{array}$ & $\begin{array}{l}\text { "Casais excessivamente preocupados com o futuro, que poupam } \\
\text { uma vida mal vivida faz com que a saúde para "curtir" a } \\
\text { aposentadoria não feja a esperada. A mesquinharia excessiva tira } \\
\text { o pique para viver momentos de prazer." (Cerbasi, 2004, p. 45). }\end{array}$ \\
\cline { 2 - 3 } & $\begin{array}{l}\text { Adeus } \\
\text { Aposentadoria }\end{array}$ & $\begin{array}{l}\text { "As perguntas a seguir foram elaboradas para pessoas de } \\
\text { quaisquer idade e situação financeira e vão avaliar até que ponto } \\
\text { você está preparado para esta fase que se convencionou chamar } \\
\text { de aposentadoria. Reflita cuidadosamente antes de dar suas } \\
\text { respostas. } \\
\text { (Cerbasi, 2014, p. 28). }\end{array}$ \\
\hline
\end{tabular}

Fonte: Elaboração própria, segundo análise no software Atlas Ti

\subsection{Inferência e interpretação}

$\mathrm{Na}$ inferência e interpretação são confrontadas as hipóteses do estudo com os achados da fase descritiva da análise de conteúdo efetuada no item 4.1., bem como possíveis interpretações para os fenômenos identificados. As hipóteses do estudo foram baseadas no em dados oficiais de acesso ao mercado de capitais (i); de dificuldade financeira das pessoas (ii) e do conhecimento financeiro das populações (iii).

Em relação ao primeiro ponto (i) presume-se que o foco da literatura será maior em "Gestão de Ativos e Investimentos" quanto maior a parcela da população que participa ou tem acesso ao mercado de capitais. Nesse sentido era esperado que o foco da produção norte-americana seria em "Gestão de Ativos e Investimentos". Em sequência (ii), presume-se que o foco da literatura será maior em "Planejamento Financeiro" quanto maior a dificuldade financeira da população em relação às despesas e dívidas (o que denominamos aqui de dificuldade financeira). Assim sendo, era esperado que o foco da produção brasileira se daria nessa codificação. Por fim (iii), presume-se que quanto maior a educação financeira ou conhecimento financeiro de uma população, menor a tendência ao endividamento e nesse sentido maior espaço para a codificação "Gestão de Ativos e Investimentos", assim como exposto por Saleh e Saleh (2013). Nesse sentido, esperava-se que a literatura de autores norte-americanos tivesse um foco maior em "Gestão de Ativos e Investimentos" quando comparada com a literatura de autores brasileiros.

Quanto à confrontação das hipóteses, percebe-se nas análises descritivas acima que quando tomadas em perspectiva comparativa, a hipótese do estudo foi parcialmente rejeitada já que em ambas as literaturas há a predominância de assuntos ligados a codificação "Gestão de Ativos e Investimentos" com 1.010 citações de autores norte-americanos (58,63\% do total) e 627 citações em autores brasileiros (46,72\% do total). Podemos interpretar o resultado sob duas óticas.

A primeira seria ligada ao fato de que os consumidores de literatura em finanças pessoais em ambos os mercados tenham interesse direto no assunto "Gestão de Ativos e Investimentos", já que os mesmos não seriam pessoas com dificuldades financeiras, pois teriam capital disponível para investimentos. Isso poderia indicar que as pessoas com dificuldades financeiras não demandam literatura com esse foco, já que por sua própria característica não teriam capital disponível para suas contas e dívidas e consequentemente para gastos em livros de auto-ajuda finanças pessoais. Já a segunda forma de interpretação seria uma forma de mimetismo da literatura por parte dos autores brasileiros que poderiam enxergar o mercado norte-americano (mais antigo, tradicional e robusto na área) como modelo de sucesso ou mesmo como influência para suas obras.

Contudo, verificamos que apesar da "Gestão de Ativos e Investimentos" ser o foco de ambas as literaturas, o "Planejamento Financeiro" em autores brasileiros também tem peso relevante quando comparado aos norte-americanos, já que em termos relativos $36,74 \%$ contra $22 \%$ respectivamente, além das amplitudes entre o primeiro código e o segundo serem de 36,93\% e 9,98\% também respectivamente. Isso significa que embora "Gestão de Ativos e Investimentos" seja o foco de ambas as literaturas, no mercado de autores brasileiros a codificação "Planejamento Financeiro" tem participação mais relevante e próxima à "Gestão de Ativos e Investimentos" quando comparado com o mercado de autores norteamericanos. Dessa forma a hipótese levantada não foi rejeitada por completo. 


\section{CONCLUSÕES E CONSIDERAÇÕES FINAIS}

O objetivo desse estudo qualitativo foi efetuar uma análise descritiva, comparativa e explicativa dos cinco best-sellers em finanças pessoais de autores brasileiros e norte-americanos com intuito de identificar padrões nas respectivas literaturas, interpretando os resultados obtidos com o acesso ao mercado de capitais em ambos os países, as dificuldades financeiras e o conhecimento financeiro de suas populações.

Para atingir tal objetivo, usamos a análise de conteúdo (Bardin, 2006) buscando codificar as obras selecionadas, isto, é aquelas com maiores volumes de vendas entre $2010-2019$. As codificações foram baseadas no programa do Certified Financial Planning Standards Board (CFSP): "Planejamento Financeiro", "Gestão de Ativos e Investimentos", "Planejamento de Aposentadoria", "Planejamento de Riscos e Seguros", "Planejamento Fiscal" e "Planejamento Sucessório".

As hipóteses do estudo são baseadas em dados oficiais de participação e acesso ao mercado de capitais, dificuldades financeiras e conhecimento financeiro de suas populações. Nessa direção, a hipótese do trabalho aponta que o foco da literatura dos autores norte-americanos seria na codificação "Gestão de Ativos e Investimentos" e nos autores brasileiros a codificação "Planejamento Financeiro" dada a maior presença da população norte-americana no mercado de capitais quando comparada a brasileira, bem como o grau de dificuldade financeira que se encontram ambas as populações e dada a diferença entre o conhecimento financeiro entre as mesmas.

Os resultados da análise demonstraram que a hipótese foi parcialmente rejeitada já que em ambas as literaturas o foco principal é em "Gestão de Ativos e Investimentos", porém no mercado brasileiro a amplitude em relação ao "Planejamento Financeiro" é significativamente menor quando comparada àquela observada nos autores norte-americanos.

Inferimos que o foco em "Gestão de Ativos e Investimentos" pode ser explicado ou pelo fato dos consumidores desse tipo de literatura têm interesse direto no tocante aos temas ligados a essa codificação e estão inseridos (ou pretendendo se inserir) no mercado de investimentos financeiros, sobretudo o de capitais, tendo capital disponível para esse fim, buscando assim conhecimento específico nessa codificação. Outra forma de interpretação estaria em um certo grau de mimetismo por parte da literatura oriunda de autores brasileiros, que poderiam entender o mercado norte-americano como modelo (de sucesso) ou influência direta dos autores e livros deste país cuja literatura é mais antiga e robusta.

Já a diferença de amplitude entre "Gestão de Ativos e Investimentos" e "Planejamento Financeiro" entre ambas as literaturas, em que a brasileira é sensivelmente menor que a americana, além do que já apontado acima (acesso ao mercado) indica como apontado por Saleh e Saleh (2013) em que pessoas com maior educação financeira tendem a ser menos endividados e com dificuldades em pagar contas, dessa forma, dada a diferença entre o conhecimento financeiro entre a população norte-americana e a brasileira, como evidenciado pelo exame PISA (2015) seria esperado que os autores brasileiros lançassem mão da codificação "Planejamento Financeiro".

Esse estudo busca contribuir com o campo da educação financeira e finanças pessoais, através do entendimento de uma importante ferramenta de formação (livros de autoajuda financeira) nesse campo dada a falta de formação em educação financeira por parte da população, notadamente a brasileira.

\section{REFERÊNCIAS}

ARCURI, N.. Me Poupe. Editora Sextante. Rio de Janeiro, $1^{\text {a }}$ edição, 2018.

ASBOHR, M.; FERREIRA, N. Livros de Autoajuda para Crianças: Uma Coleção. Pro-Posiçóes. v.13, n. 1, p.186199, 2002.

B3. Histórico de pessoas físicas na Bolsa de Valores. 2020. Disponível em http://www.b3.com.br/pt br/market-datae-indices/servicos-de-dados/market-data/consultas/mercado-a-vista/historico-pessoas-fisicas/. Acesso em 31 de jan. 2020.

BARDIN, L. Análise de conteúdo. Edições 70. Lisboa, 1977.

BESSA, S.; FERMINIANO, M. B. ; CORIA, M. D. Compreensão econômica de estudantes entre 10 e 15 anos. Psicologia \& Sociedade, n. 26, v. 2, p. 410-419, 2014.

BORBA, J. M. P. A literatura de autoajuda financeira e o capitalismo de consumo. In V ENEC - Encontro Nacional de Estudos do Consumo do I Encontro Luso-Brasileiro de Estudos do Consumo Tendências e ideologias do consumo no mundo contemporâneo. Rio de Janeiro, p. 1-15, 2010.

CAMPBELL, J. Y.. Household finance. The Journal of Finance, v. 61, n. 4, p. 1553-1604, 2006.

CERBASI, G. Casais inteligentes enriquecem juntos. Editora Gente. São Paulo, 20ª edição, 2004.

CERBASI, G. Adeus Aposentadoria: como garantir seu futuro sem depender dos outros. Editora Sextante. Rio de Janeiro, 2014. 
CHIZZOTTI, A. Pesquisa em ciências humanas e sociais. Editora Cortez. São Paulo, 2ª edição, 2006.

CNC - Confederação Nacional Do Comércio De Bens, Serviços E Turismo. Pesquisa Nacional de Endividamento e Inadimplência do Consumidor (PEIC). 2019.

FARRELL, L; $\quad$ FRY, T.R.L; $\quad$ RISSE, L. The significance of financial selfeffcacy in explaining women's personal finance behaviour. Journal of Economic Psychology. V. 54, p. 85-99, 2016.

GRAHAM, B. The Intelligent Investor. Editora Harper Business Essentials, 2003.

HILL, N. Think and Grow Rich. Editora The Ralston Society. Meriden, Conn., 2000.

KIYOSAKI, R.; LECHTER, S. Rich Dad Poor Dad. Editora Plata Publishing, 2011.

MARCONI, M.; LAKATOS, E M. Fundamentos de metodologia científica. Editora Atlas. São Paulo, 5aa edição, 2003.

MOZZATO, Anelise Rebelato; GRZYBOVSKI, Denize. Análise de Conteúdo como Técnica de Análise de Dados Qualitativos no Campo da Administração: Potencial e Desafios. RAC. Curitiba, v. 15, n. 4, p. 731-747, 2011.

NIGRO, T. Do Mil ao Milhão: sem cortar o cafezinho. Editora Harper Collins. Rio de Janeiro, 1ª edição, 2018.

OCDE. Resultados do PISA 2015, 2017. Disponível em www.ocde.org. Acesso em 15 de junho de 2019.

PEREIRA, F.; CAVALCANTE, A.; CROCCO, M.. Um plano nacional de capacitação financeira, Economia e Sociedade, v. 28, n. 2, p. 541-561, 2019.

PIRES, D., LIMA, O., DALONGARO, R., SILVA, P. S., SILVEIRA, J.. Educação Financeira como Estratégia para Inclusão de Jovens na Bolsa de Valores. Encontros Científicos-Tourism \& Management Studies, n.3, p. 720-730, 2013.

PLANEJAR - Associação Brasileira de Planejadores Financeiros - Programa Detalhado do Exame da Certificação CFP (Certified Financial Planner), 2019.

RAMSEY, D. The total money makeover. Ed. T. Nelson, Tennessee, 2007.

RCF - Relatório de Cidadania Finaceira, 2018. Disponível em: < https://www.bcb.gov.br/nor/relcidfin/docs/Relatorio Cidadania Financeira.pdf >. Acesso em: 04 jun. 2019.

ROQUETE, I.; LAUREANO, R.; BOTELHO, M. C. Conhecimento financeiro de estudantes universitários na vertente do crédito. Tourism \& Management Studies, Special Issue, n. 10, p. 129 - 139, 2014.

SAITO, A. T.; SANTANA, F. de A.; SAVOIA, J. R. F. Paradigmas da educação financeira no Brasil. Revista de Administração de Empresas. Rio de Janeiro, v. 41, n. 6, p. 1121-41, 2007.

SALEH, A. M.; SALEH, P. O Elemento Financeiro e a Educação Para O Consumo Responsável. Educação em Revista. Belo Horizonte, v. 29, n. 04, p. 189-214, dez. 2013.

SANTANA, M. V. S. Educação financeira no brasil: Um estudo de caso. Belo Horizonte, 2014.

SARAIVA, K. S. Os sujeitos endividados e a Educação Financeira. Educar em Revista. Curitiba, n. 66, p. 157173, 2017.

SETHI, R. I Will Teach You To Be Rich. Editora Workman Publishing, 2009.

SPC - Serviço de Proteção ao Crédito. Pesquisa de Educação Financeira: Orçamento Pessoal e Endividamento. Jan. 2019.

SILVA, T. P.; MAGRO, C. B.; GORLA, M. C.; NAKAMURA, W. T. Financial education level of high school students and its economics reflections. Revista de Administração, v. 52, p. 285-303, 2017.

SPC - Serviço de Proteção ao Crédito. Pesquisa de Inadimplência de Pessoas Físicas. Mar. 2019.

STATISTA. Share of families with debt in the US in 2016, 2017. Disponível em: https://www.statista.com/statistics/247874/amount-of-family-debt-distributed-by-type-of-debt/ .Acesso em: 4 de jun. 2019.

US CENSUS BUREAU. Families and households, 2018 . Disponível em:
https://www.census.gov/topics/families/families-and-households.html . Acesso em: 8 de jun. 2020.

VEIGA, R.T.; AVELAR, C.; MOURA, L.R.C.; HIGUCHI, A.K.. Validação de escalas para investigar a gestão financeira pessoa. Revista Brasileira de Gestão de Negócios, v.21, n.2, p.332-348, 2019.

WIZARD, Carlos. Desperte o milionário que há em você. Editora Gente. SÃO Paulo, 2012. 
